\title{
Mobile Technology Applications for Manufacturing, Reduction of Muda (Waste) and the Effect on Manufacturing Economy and Efficiency
}

\author{
http://dx.doi.org/10.3991/ijim.v8i4.3797 \\ A.M. Huenerfauth \\ Indiana State University, Terre Haute, IN, United States
}

\begin{abstract}
Mobile devices in the manufacturing setting offer mobility and information whenever and wherever it is needed; these advantages allow for a more efficient workflow and allow the user to make more informed decisions. Due to these advantages, companies are reducing muda (waste) by using mobile devices (implementing Lean Manufacturing) and therefore saving money. Some of the mobile applications discussed in this paper are the following: Augmented Reality for assembly training, pruefcubing, remotelymonitored shop floors, statistical process control (SPC), and change requests for construction, and the two types of muda (waste) reduced by these mobile applications are "unnecessary / excess motion and defects ${ }^{3}$."
\end{abstract}

Index Terms-Augmented Reality, Lean Manufacturing, Mobile Device and Muda (Waste)

\section{INTRODUCTION}

As the functionality of mobile devices has increased, so have the possible applications for this technology in the manufacturing environment. A major advantage of mobile technology is that it can provide information to the user at any time and location, which will allow the users to make more informed decisions, be more efficient, reduce waste (implement Lean manufacturing) and save their company money. Some of the unique manufacturing applications for mobile technology include Augmented Reality for assembly training, pruefcubing, remotely-monitored shop floors, SPC, and change requests for construction.

\section{HELPFUl HINTS}

\section{A. Mobile and Muda}

"Mobile is big business. It's projected that apps will become a bigger market than CDs by 2012 . It is only natural for it to exert an influence on the learning \& training market as well ${ }^{2}$." According to Vairaktaraki ${ }^{7}$ in his journal article Worker Cross-Training in Paced Assembly Lines:

Industries such as aircraft, fire-engine, and automobile assembly have production cycles of a few hours and are labor intensive. In spite of increased automation in such industries, human capital remains the most expensive and important contributor to a flexible production system.

There are a number of issues with training new personnel: training requires a significant effort on the part of the staff; information may be missed when it is being transferred; the trainee may only watch someone else perform the training; and the training manuals may not be effective in describing the required actions.

According to McBride's ${ }^{3}$ article The 7 Manufacturing Wastes:

Waste elimination is one of the most effective ways to increase the profitability of any business. Processes either add value or waste to the production of a good or service. The seven wastes originated in Japan, where waste is known as "muda." "The seven wastes" is a tool to further categorize "muda" and was originally developed by Toyota's Chief Engineer Taiichi Ohno as the core of the Toyota Production System, also known as Lean Manufacturing.

The two types of muda (waste) saved by the mobile applications discussed in this article are "unnecessary / excess motion and defects ${ }^{3}$." McBride ${ }^{3}$ describes unnecessary / excess motion as "motions that a user performs that do not add value to the final product." He states that "defects resulting in rework or scrap are a tremendous cost to organizations. Associated costs include quarantining inventory, re-inspecting, rescheduling, and capacity loss.".

\section{B. Augmented Reality for Assembly Training}

BMW has implemented a test environment in which new personnel are given assembly training using Augmented Reality technology; augmented reality superimposes information in the form of audio, text, graphics and other sense enhancements over a real world environment. Morkos describes in his article Mobile devices within manufacturing environments: a BMW applicability study that "ultra-mobile personal computers provide the function of a computer in a compact, mobile configuration and augmented reality (wearable mobile devices) in a production environment where hands free operation is essentiall." Some of the advantages of Augmented Reality technology are that it is "flexible (hands-free); allows realtime transfer of information; has the ability to identify where the user is and the orientation of their viewing perspective; and has the ability to identify the user's location in reference to their surroundings." See the image of a technician replacing parts in a BMW in Figure 1: Augmented Reality Overlays.

According to Webel's ${ }^{9}$ article Augmented Reality Training for Assembly and Maintenance Skills: "Augmented Reality (AR) points out to be a good technology for training in the field of maintenance and assembly, as instructions or rather location-dependent information can be directly linked and/or attached to physical objects." 


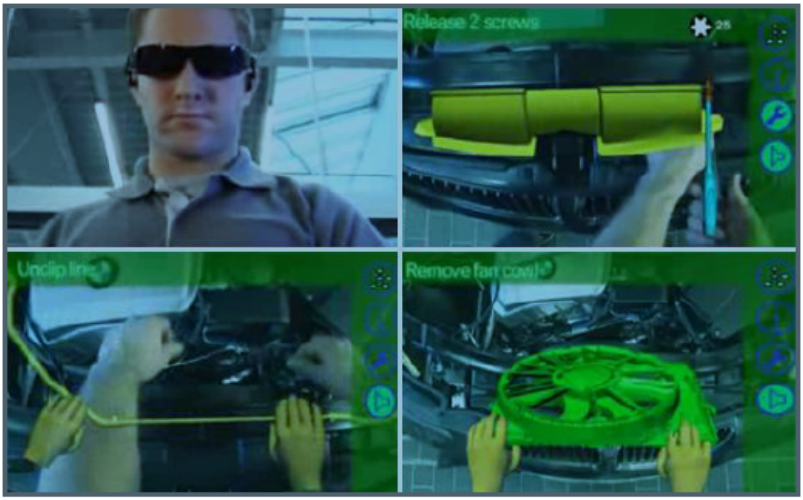

Figure 1. Augmented Reality Overlays ${ }^{4}$

There are several options for the implementations for the hardware of Augmented Reality; it can be displayed on a smartphone or through the glasses of a head-mounted display. For assembly training, the head-mounted display makes the most sense, because it is hands-free. Within the head-mounted display is a tracking system that lets the system know the location, perspective and orientation of the user with respect to the BMW. The mobile computer matches focal points on the BMW with 3D images that are part of the library of assembly processes. This way, it allows the 3D image to overlay the actual image the user is viewing through his glasses. See the depiction of the user wearing the head-mounted display and the image that the user would see through the display in Figure 2: HeadMounted Display (2a) and Image through Display (2b).

The videos and audio commands are stored in a server which is connected to a wireless router. The trainee can steer or command the mobile device or head-mounted display, which can request a scenario and feeds back a compiled scenario to the mobile device / head-mounted display. The display then shows an output (visual and audio) to the user. See Figure 3: Diagram of Augmented Reality Process.

Using this technology as a training guide not only standardizes the training for assembling parts, but it also saves the time of a trainer stepping the trainee through the whole process. The standardization of the training means that everyone using the program receives the same training and therefore one of the forms of muda (waste) namely unnecessary / excess motion (people or equipment moving or walking more than is required to perform the processing) is reduced ${ }^{3}$. This is a major cost savings for companies and can be implemented on a mass scale meaning the savings occur everytime someone trains with Augmented Reality instead of watching a trainer for a period of time. Performing tasks yourself and being hands-on in the training is also a much more effective training technique, because trainees can learn from their mistakes as they are working through a problem.

\section{Pruefcubing}

Another use of mobile device in manufacturing is for pruefcubing. According to Morkos ${ }^{4}$, pruefcubing is "a process in which an OEM supplier is able to physically test how their part or subsystem fits and mates with the vehicle it is designed for." Pruefcubing is a way for part suppliers to ensure parts match specification through verification. High precision is used to manufacture a zero-
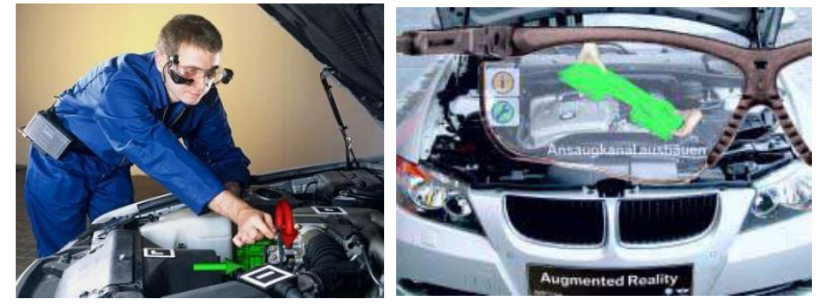

Figure 2. a) Head-mounted display; b) Image Through Display ${ }^{4}$

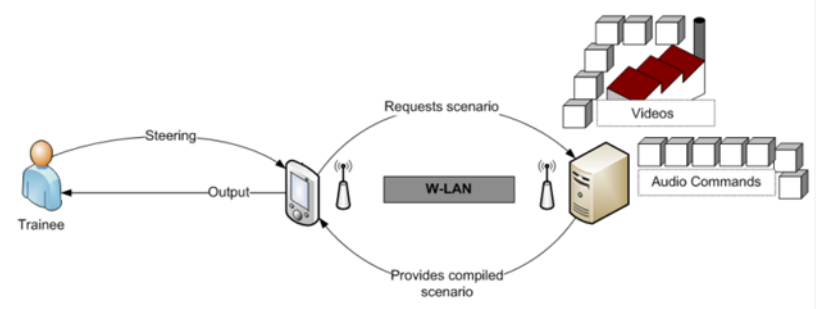

Figure 3. Diagram of Augmented Reality Process ${ }^{4}$

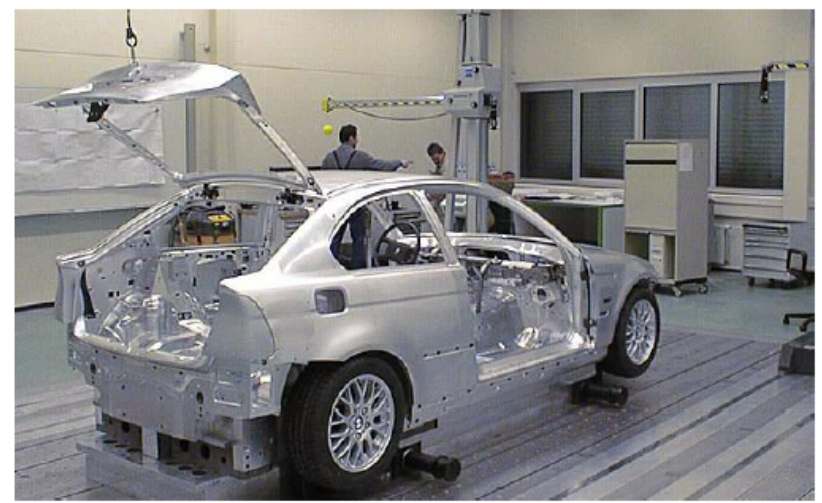

Figure 4. High-Precision Vehicle Ready for Pruefcubing ${ }^{4}$

tolerance vehicle meaning it has the perfect shape. Suppliers come in to identify the proper tolerances, so that all their parts will fit together. Currently, there is no standardized method for pruefcubing, and the general practice is inefficent and very disorganized. Some suppliers take measurements in notebooks, while others take pictures of all the interfaces of the parts. See Figure 4: HighPrecisioned Vehicle Ready for Pruefcubing.

Using a mobile device for pruefcubing offers a more powerful and structured process: measurements can be inputed on-the-fly and edited. With a mobile app, the user can receive feedback if one of the measurements is off or if there is an issue with some of the tolerances. With hand measurements in a notebook, the pruefcuber may not know they have an issue with their math until they get back to the office. By then, the high precision car may not be available any more for measurement-taking. Another advantage would be that this app could collect the pruefcubers' information and share it back with the vehicle designer. See Figure 5: Mobile App to Gather Pruefcubing Measurements.

Since using a mobile device provides a more efficient and standardized process for pruefcubing, it reduces a type of muda (waste) called defects resulting in to a monetary advantage for the company as well ${ }^{3}$. If the pruefcuber does not know that there is an issue with the measurements until they get back to the office, this could be a costly mis- 

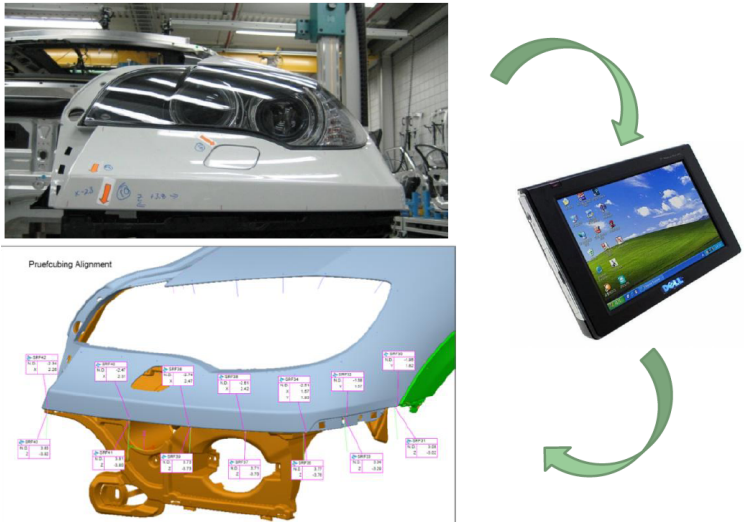

Figure 5. Mobile App to Gather Pruefcubing Measurements ${ }^{4}$

take. The pruefcuber may need to travel back to the vehicle designer to gather more measurements if the vehicle is available to measure. If the pruefcuber never realized that there are mistakes in their numbers, then the indvidual parts may be formed incorrectly. This is even more costly for the company, because now they will need to deal with product recalls and customer complaints in the field. The mobile device can prevent all of this by giving the pruefcuber immediate feedback if tolerances are not lining up during the measurement-taking process.

\section{Remotely-monitored shop floors}

Another application of mobile devices for the manufacturing setting is to create a remotely-monitored, mobile shop floor. According to Rourke ${ }^{6}$ from ProfitKey International:

We will soon have the opportunity to run our manufacturing companies and shop floors remotely; from being literally on the floor and in your offices, dialing up reports without having to bounce around from department to department, or building to building, to being at home, on the road, or on vacation and not have to worry about bottlenecks or waiting on others to send YOU reports. Soon you will be able to keep tabs on all major jobs, projects, etc. remotely and wirelessly.

A manager can keep track of the status of his shop floor anywhere and anytime he needs to with his mobile device. According to Waurzyniak's ${ }^{8}$ article Shop-Floor Monitoring Critical to Improving Factory Processes, "Employing shop-floor monitoring solutions gives manufacturers a way to visualize what's wrong with their processes." With a remote-monitoring app, the smartphone could send push notifications to the smartphone if there is an issue with a machine on the shop floor; if the product is being produced out of specification or if inventory is low.

If a sensor is activated on the machine shop floor, then the wireless monitoring unit will send up a signal to the central monitoring station. This station then can send a phone call, text message or even a smartphone app notification that there is a problem. The smartphone can also be used to monitor the status of the shop floor. See Figure 6: Mobile Shop Floor Diagram.

Also, one manager can monitor several shop floors at once; the application allows for efficient monitoring of shop floors as well as smooth escalation of issues on the floor. Operators on the floor do not need to call the manager and locate him, because the system will automatically send the information to the manager. The quick notifica-

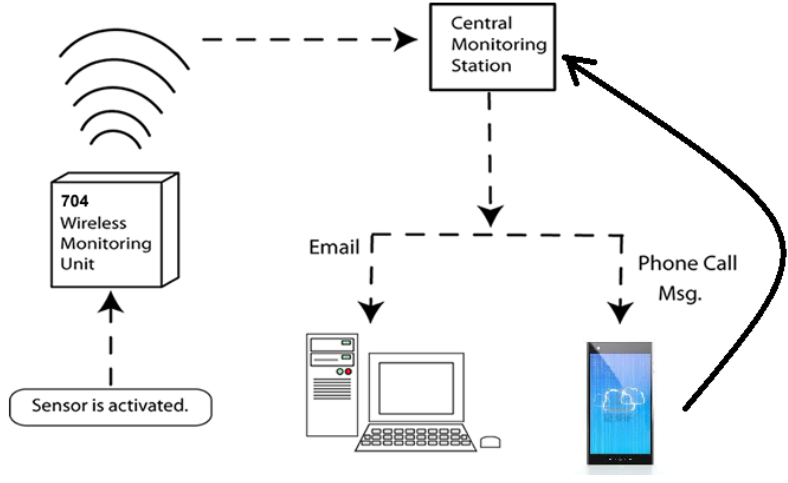

Figure 6. Mobile Shop Floor Diagram

tion to the manager can help the operators get the shop back up and running in a timely manner, so that production time is not lost. Also, the manager does not need to call the shop floor to find out if an issue has been resolved, because he can sign into the mobile app to see the realtime status of the shop floor. These efficiencies will reduce the type of muda (waste) called defects which will allow for a much more streamlined process with less downtime; this will translate into major cost savings over time for the company ${ }^{3}$.

\section{E. Statistical Process Control (SPC)}

Mobile technology can be used to monitor the status of a shop floor remotely, and it can be used as a tool on the manufacturing floor. Van Rens writes in his article How Mobile Technology Is Changing the Plant Floor:

Statistical process control works to ensure that every product that is created conforms exactly to the specifications required for standard quality. These measurements are entered into a computer, which then scans products to detect variation and remove it from a production line.

SPC is a process engineering term used to describe the guidelines for keeping a process in control (running within operating range and producing products within specification).

Rens ${ }^{5}$ continues to explain that mobile devices can be used in the following way:

A manufacturing executive can therefore manage an entire production floor based solely on the numbers that stream into a tablet or smartphone. Most importantly, when a major manufacturing decision has to be made, an executive will be able to trust in the integrity of the data and act accordingly.

Usually specification data of a product (width, length, diameter, etc.) is captured in spreadsheets on local a computer or is hand written on sheets. When there is an issue with a machine on the shop floor, then the executive needs to scan this data to make a quick assessment of what the problem is. If all the data is funneled into a mobile device and analyzed, then the executive can make a more informed and faster decision. This means that there is less downtime for the machines and a reduction in the costs of manufacturing delays. By reducing all these unnecessary / excessive motions (muda/waste), then the company is moving toward becoming more Lean ${ }^{3}$. As the manufacturing associates enter information at their workstations, the data is funneled to a wireless router that sends the information to an executive's smartphone. See Figure 7: Mobile Shop Floor SPC Model. 


\section{F. Change Requests for Construction}

Another type of manufacturing is the manufacture of homes and offices for the construction industry. Eddy ${ }^{1}$ notes in his article Mobile Technology Positively Impacts Manufacturing, Construction:

The construction industry particularly benefits from mobile devices, which, for example, can eliminate the need to haul bulky sets of plans and 4-inch-thick books of project specifications to the job site.

Electronically being about to pull up project plans without hauling large documents everywhere is a major advantage of the mobile devices.

The field of construction is heavily burdened with documentation concerning change orders and change requests. A mobile office is set up at the construction site, so that the project manager can have a place to review plans and make phone calls. However if the construction team needs to deviate from the architect's original plans, then the architect must be notified via email or the phone, the architect must be shown the change, sign off on the change and then send the signed change order back to the project manager. Sometimes signed off change requests can take up to a week to process. In that interim, construction may be halted completely waiting on the decision of the architect. The ability to electronically send change requests to architects, have the architects review the change and electronically sign off on those requests would provide a much more efficient workflow by reducing the type of muda (waste) called unnecessary / excess motion which translates into saving money on manufacturing downtime ${ }^{3}$. See Figure 8: Change Requests with Mobile Devices.

\section{CONCLUSION}

Mobile devices have exploded in popularity in the manufacturing market, and the functionality of the mobile devices has expanded to meet the growing needs of manufacturing systems. There are a number of applications for mobile devices in the manufacturing environment that streamline the workflow of the user and therefore reduce / eliminate muda (waste) in the manufacturing. The two specific types of muda (waste) that were saved in these examples were "unnecessary / excess motion and defects ${ }^{3}$." Reduction in these two types of waste means the manufacturing of the company is moving towards becoming more Lean in its manufacturing overall which translates into cost savings for the company overall.

\section{REFERENCES}

[1] Eddy, N. (2013). Mobile Technology Positively Impacts Manufacturing, Construction. eWeek.com. Retrieved March 5, 2014 from http://www.eweek.com/small-business/mobile-technologypositively-impacts-manufacturing-construction/

[2] Garg, Amit. (2010). Will Mobile Apps Change Training Forever? Upsidelearning.com. Retrieved March 5, 2014 from http://www.upsidelearning.com/blog/index.php/2010/09/30/willmobile-apps-change-training-forever/

[3] McBride, David (2012). The 7 Manufacturing Wastes. EMS Consulting Group. Retrieved April 3, 2014 from http://www.emsstrategies.com/dm090203article2.html

[4] Morkos, B., Taiber, J., Summers, J., Mears, L., Fadel, G. \& Rilka, T. (2012). Mobile devices within manufacturing environments: a BMW applicability study. International Journal on Interactive Design and Manufacturing (IJIDeM), 6(2), 101-111. http://dx.doi.org/10.1007/s12008-012-0148-x

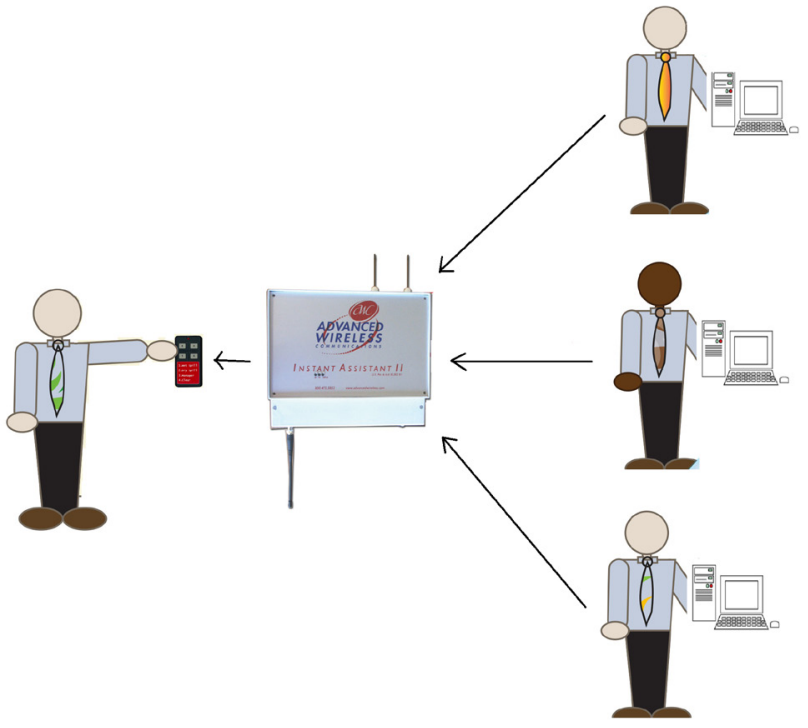

Figure 7. Mobile Shop Floor SPC Model

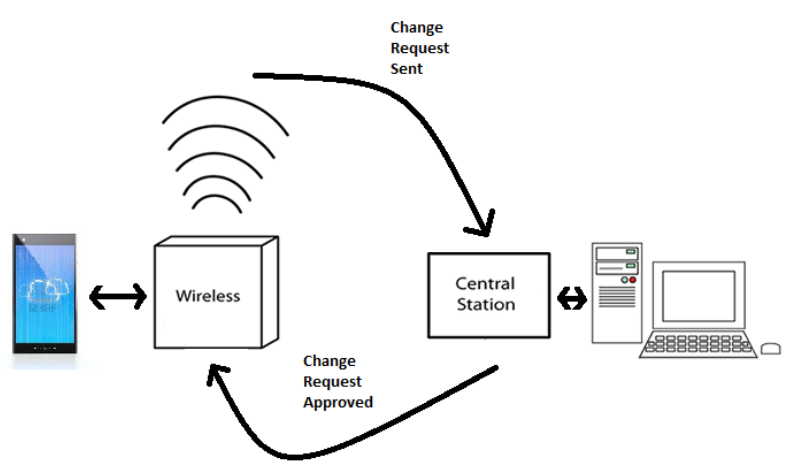

Figure 8. Change Requests with Mobile Devices

[5] Rens, E. (2013). How Mobile Technology is Changing the Plant Floor. InfinityQS.com. Retrieved March 5, 2014 from http://www.infinityqs.com/blog/how-mobile-technologychanging-plant-floor

[6] Rourke, J. (2011). Using Mobile Devices To Run Your Shop Floor. Profitkey.com. Retrieved March 5, 2014 from http://blog.profitkey.com/2011/08/31/using-mobile-devices-torun-your-shop-floor/

[7] Vairaktarakis, G. \& Winch, J. (1999). Worker Cross-Training in Paced Assembly Lines. Journal of Manufacturing \& Service Operations Management archive, 1(2), 112-131. http://dx.doi.org/10.1287/msom.1.2.112

[8] Waurzyniak, P. (2013). Shop-Floor Monitoring Critical to Improving Factory Processes. Sme.org. Retrieved March 5, 2014 from http://www.sme.org/MEMagazine/Article.aspx?id=74143

[9] Webel, S., Bockholt, U., Engelke, T., Olbrich, M., Peveri, M. \& Preusche, C. (2011). Augmented Reality Training for Assembly and Maintenance Skills. BIO Web of Conferences, 1, 00097. http://dx.doi.org/10.1051/bioconf/20110100097

\section{AUTHOR}

M. Huenerfauth is a $\mathrm{PhD}$ in Technology Management student at Indiana State University, United States, $200 \mathrm{~N}$ 7th St, Terre Haute, IN 47809.

Submitted 24 April 2014. Published as resubmitted by the authors 14 October 2014. 